\title{
Investigation of the deformation characteristics of water-saturated coal samples with a hole for estimating the discharge of the reservoir during hydrolysis
}

\author{
Oleh Usov ${ }^{1, *}$, Yurii Poliakov ${ }^{1}$, and Liudmyla Andriievska ${ }^{2}$ \\ ${ }^{1}$ Institute of Geotechnical Mechanics named by N. Poljakov of National Academy of Sciences of \\ Ukraine, 49005, Dnipro, Simferopolska Str., 2a, Ukraine \\ ${ }^{2}$ State University of Internal Affairs, 49005, Dnipro, Gagarina Ave, 26
}

\begin{abstract}
The deformation characteristics of the uniaxial compression of the same sample with a central hole at different humidity are presented. The sample was saturated with water under pressure through the hole. The deformation curve has the form of a one-term power dependence. Increasing the humidity by $2 \%$ reduces axial stresses by 3.2 times, and the modulus of elasticity - by 2.5 times with the same deformation.
\end{abstract}

\section{Introduction}

In order to combat sudden emissions, high-pressure water is injected into the coal seam [1]. The main effect of hydraulic treatment is to unload the forces of rock pressure in the area around the coal mine bottom. It is detected by seismic measurements and gas emission measurements in control wells. Unloading the near-bottom part of the reservoir dramatically reduces the likelihood of its dynamic destruction - a sudden release [2].

Initially it was believed that the unloading of the reservoir is caused by the development of cracks under the action of high water pressure. This hydropower factor explains the increase in permeability of oil reservoirs as a result of their fracturing. In the bottomhole part of outburst coal seams, the development of cracks due to water pressure leads to hydraulic formation of the reservoir. Hydro-pressing shows up in the form of coal bed movement into the mine working area. [3].

But, with the accumulation of practical experience in the use of hydraulic treatment, the ideas about the main factors of reservoir unloading changed. It turned out that the unloading of the reservoir is observed without its movement into the production area of mine. This treatment mode is called the hydro-loosening of the formation [4]. It is observed with a greater length of the well filtration chamber than with hydro-pressing. And the water pressure during hydrolysis is less than with hydro-pressing. Therefore, the mode of hydroloosening cannot be explained solely by the hydraulic force factor.

An explanation of this problem began to be sought in changing the physic-mechanical properties of coal when it is saturated with water. The first publications on the experimental

*Corresponding author: usov.o.a@gmail.com 
study of the effect of moisture on the physic-mechanical properties of coal appeared more than 50 years ago [5]. Later, theoretical models of the hydro-loosening process appeared, taking into account the effect of moisture on the physical and mechanical properties of coal. First of all, the factor of reducing the strength of coal with an increase in its moisture content was taken into account [6]. The calculations also introduced changes in the coefficients of internal and external friction [7]. On the basis of these works, the concept of rock-force unloading of a coal seam has arisen [8].

It is based on reducing the strength of a wet coal seam. Its strength becomes less than the mechanical stresses due to the weight of the overlying stratum of rocks - rock pressure. This leads to the deformation of coal beyond the limit of its strength and reduces the bearing capacity of the edge part of the coal bed. At the same time cracks develop in the corner. But the main factor in their development is rock pressure, not water pressure. As a result of reducing the bearing capacity of the edge part of the reservoir, the zone of maximum rock pressure shifts to its depth.

The rock-force factor well explains all the observations of the hydro-loosening process at high loads on the edge of the coal seam with rock pressure. The value of rock pressure should not be below $70 \%$ of the breaking point of coal. This condition is explained by the fact that the strength of wet samples of coal is reduced by $~ 30 \%[4,5]$. With a smaller value of rock pressure than the strength of wet coal, the bearing capacity of the edge part of the reservoir does not decrease. And it should not unload. But the unloading is still happening, although not so intense. This is evidenced by the results of monitoring the state of the reservoir on seismic signals, changes in the dynamics of gas emission and water injection pressure.

In order to explain the reservoir unloading at a non-high rock pressure, in recent years, the concept of deformational unloading of the reservoir has been developed [9]. It is not based on reducing the breaking point, but on increasing of the pliability of the wet coal seam. Coal pliability is determined by the Young's modulus of elasticity and the Poisson's lateral strain coefficient. With increasing humidity, the Young's modulus decreases, and the Poisson's ratio increases. The first theoretical estimates showed that the mechanical stresses in the wet area of the reservoir decrease. Outside the zone of wetting stresses in the reservoir increase. These results confirmed the consistency of the assumption about the change in the pliability of wet coal as an important unloading factor at not high rock pressure. However, for reliable mathematical modeling of the strain relief of the formation, the available experimental data is not enough. And they do not always agree with each other.

When conducting experiments, it is very important to saturate the coal samples under conditions that correspond to the process of real injection of water into the formation. First of all, this refers to the similarity of filtration flows.

Wells for injection are most often drilled from preparatory workings in the direction of the coal seam up to $8 \mathrm{~m}$ deep. The wellhead is isolated by a sealer to a depth of $6 \mathrm{~m}$. The flow of water in the first stage of injection will be three-dimensional. And after treatment of the reservoir in the area of the well for all its thickness - two-dimensional. Sometimes the wells are drilled perpendicular to the coal seam through the rock plug between it and the mine excavation. In this case, the water flow in the reservoir will be two-dimensional during the entire period of injection.

However, all previous laboratory tests were performed for a one-dimensional axial flow through the samples. The results of simulating a two-dimensional flow with onedimensional does not correspond to the filtration parameters of real hydro-loosening [10]. It is very likely that the one-dimensional flow differs from the two-dimensional one and according to the peculiarities of moisture saturation of coal samples. To observe the 
similarity of filtration flows, we have developed a modern two-dimensional filtering device through samples with a central hole [11].

The objectives of the research are to obtain moisture-saturated coal samples using modern equipment and modern methods of deformation. Evaluation of the effect of moisture on the elastic modulus and the degree of discharge of the reservoir from rock pressure.

\section{Methods}

The experiments were conducted on samples of coal of a cubic form measuring $40 \times 40 \times 40 \mathrm{~mm}$. The center hole axis $\varnothing 8 \mathrm{~mm}$ is perpendicular to the bedding. The end plates are glued to the sample (Fig. 1a).

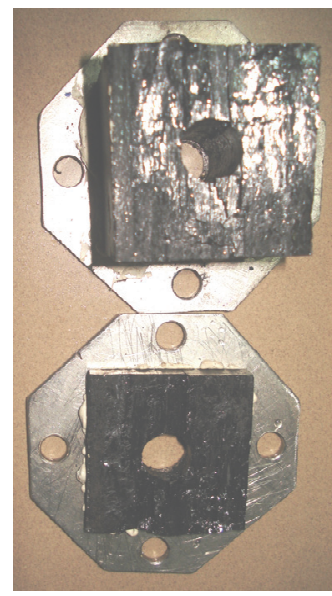

a

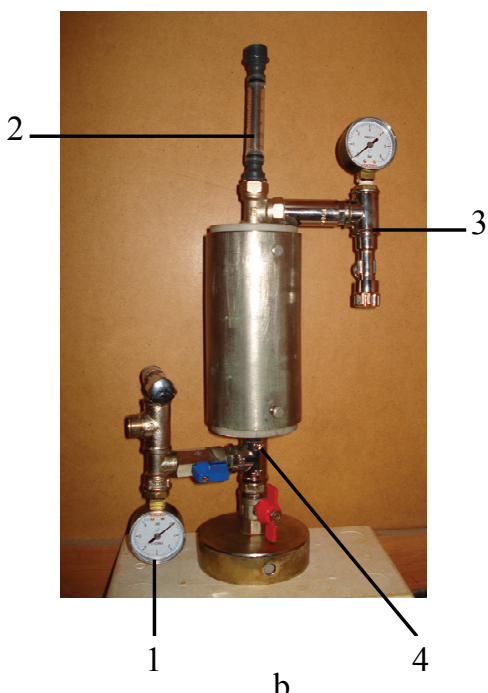

b

Fig. 1. Sample of coal and stand for its wetting: a - view of the coal sample with a hole - sample was destroyed by fractures in direction along the bedding plane after experiment; $b$ - the device [11] is a two-dimensional filtration through samples with a central hole: 1 - pressure gauge; 2 - flow meter; 3 - drainage; 4 - water channel to the hole.

The sample at natural humidity was weighed and subjected to uniaxial compression. The direction of compression coincided with the direction of the axis of the hole. The magnitude of the mechanical compression stresses $8 \mathrm{MPa}$ approximately corresponded to half of the specimen strength limit. Hole diameter $8 \mathrm{~mm}$.

After the first compression cycle, the sample was placed in a two-dimensional filtration device [11] (Fig. 1b) and saturated with water.

The water moved from the hole to the periphery of the sample. Overpressure on the contour of the hole was $0.05 \mathrm{MPa}$, injection time is 90 minutes. After saturation, the sample was removed from the instrument, weighed and subjected to uniaxial compression. The magnitude of the mechanical stresses of compression is $8 \mathrm{MPa}$.

After the second compression cycle, the sample was again placed in the device and saturated with water for 196 minutes. Overpressure on the contour of the hole was the same $0.05 \mathrm{MPa}$. After the second cycle of water saturation, the sample was weighed again and subjected to the third cycle of compression. The magnitude of the mechanical stresses of compression is $8 \mathrm{MPa}$.

At the last stage of testing, the sample was saturated under an overpressure of $0.07 \mathrm{MPa}$ 
for 50 minutes. The load on the sample in the fourth cycle was not limited. Mechanical compression stresses reached $16 \mathrm{MPa}$ at the stage of sample failure.

After each weighing of the sample was determined by the increase in moisture $\Delta W$ by the formula

$$
\Delta W=100 \cdot\left(\frac{P}{P_{0}}-1\right), \%
$$

where: $P_{0}$ - weight with natural moisture; $P$ - weight after saturation.

\section{Results and discussion}

The deformation curves of the uniaxial compression of the sample with dimensions of $40 \times 40 \times 40 \mathrm{~mm}$ and a hole $\varnothing 8 \mathrm{~mm}$ are shown in Figure 2.

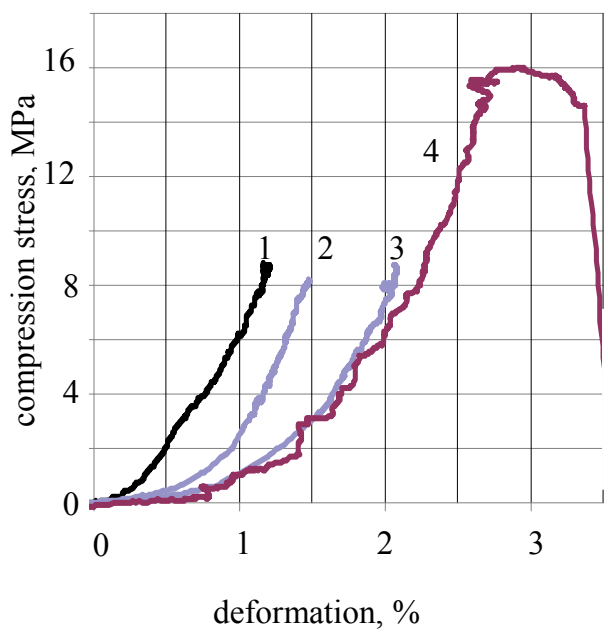

a)

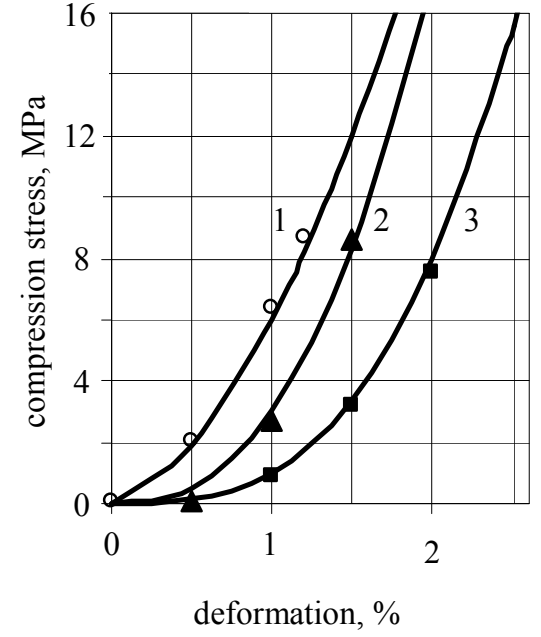

b)

Fig. 2. Uniaxial compression strain curves: a) - experiment; b) - power approximation; 1 - $\Delta W=0$; $2-\Delta W=0.9 \% ; 3-\Delta W=2 \% ; 4-\Delta W=2.2 \%$.

The "lines" in Figure 2a are continuous experimental points. "Lines" 1, 2, 3 consist of 2400 - 2900 experimental points. "Line" 4 consists of 4600 values of experimental points. Each of the "lines" 1, 2, 3 was approximated by a polynomial of the 6th degree with the correlation coefficient $R^{2}=0.9950-0.9982$. By polynomial approximation, a limited but representative number of values was chosen. They are represented by dots in Figure $2 \mathrm{~b}$.

These points were approximated by a monomial power dependence. The results of the approximation are represented by the lines Figure $2 b$. Their high correlation with experimental points is clearly visible.

The stresses $\sigma$ and deformations $\varepsilon_{p h}$ during the compression of the sample with a central hole are related by:

$$
\sigma=\vec{E} \cdot \varepsilon_{p h}{ }^{N}
$$

The proportionality coefficient has the dimension of stresses (MPa). Its value decreases with an increase in sample moisture:

$$
\bar{E}=E_{p h} \cdot\left[0.126267(\Delta W)^{2}-0.6692(\Delta W)+1\right]
$$


where $E_{p h}=6 \mathrm{MPa}$ is a power module of the sample with a hole at natural humidity.

The deformation $\varepsilon_{p h}$ has a dimension (\%). The exponent $N$ is a dimensionless quantity. It increases with an increase in sample moisture:

$$
N=N_{h} \cdot\left[-0.127765(\Delta W)^{2}+0.637824(\Delta W)+1\right]
$$

where $N_{h}=1.7$ is the power modulus of the sample with a hole at natural humidity.

The nature of the power dependence of the stress on the strain is significantly different from the Hooke's law. This may be due to several reasons. For example, the influence of skewed distortions and the misalignment of the axes of the press and the sample. These causes have a greater effect on the curvature of the lines at the very beginning of the process up to $0.2-0.3 \%$ strain or up to $1 \mathrm{MPa}$ axial stresses. With increasing stresses and strains, the position of the system stabilizes, and the curvature of the lines decreases.

It is possible that the significant curvature of the lines is due to the little-studied effect of the hole oriented along the load. A limited slip of the ends of the specimen on the press plates may be affected.

But the main reason is layered coal fracturing. The contact area of the layers with cracks perpendicular to the load is noticeably smaller than the sample area. Because of this, the pliability of a fractured sample is less than continuous. Flexibility is maximum at low loads. Under high loads, pliability is minimal due to the expansion of the contact area between the layers. This explains the concavity of the deformation curves of coal.

To calculate the parameters of deformational discharge of the reservoir with the highest accuracy, it is necessary to develop an iterative mathematical model based on the power dependence of stresses on the deformations (2-4). Formulas (2-4) should be supplemented by empirical dependences of the transverse strain coefficient on humidity for different values of the longitudinal strain.

For a more coarse qualitative assessment of the strain relief, it is more convenient to apply the already developed calculation methods. They are based on a linear dependence of the stress on the strain - Hooke's law. Therefore, it is necessary to correctly model the power law (2) by an equivalent linear law.

There are several ways to approximate a real deformation curve by a linear stress-strain dependence. They are shown in Figure 3a. Chord 4 is used in [5], which connects the origin of coordinates with the transition point to the inelastic mode of the experimental line 1 . Tangent 2 is used in [4] to the transition point to the inelastic mode of the experimental line 1. The elastic modulus values obtained by these methods do not depend on deformations. We will use ray approximation. It is depicted by line 3 in Figure 3a. Beam approximation allows to obtain the dependence of the elastic modulus $E_{c}(\mathrm{MPa})$ on the strain $\varepsilon_{p h}$ :

$$
E_{c}=100 \cdot \vec{E} \cdot \varepsilon_{p h}{ }^{N-1}
$$

Values and $N$ are determined by formulas $(3,4)$. The coefficient 100 in the right-hand side appeared because the deformation in Hooke's law $\varepsilon$ is expressed in fractions of a unit, and not in percentages, as $\varepsilon_{p h}$. They are dependant:

$$
\varepsilon_{p h}=100 \cdot \varepsilon
$$

Figure $3 \mathrm{~b}$ shows a family of $E_{c}$ values for various deformations of the sample. Line 1 is constructed according to data [5], line 2 - according to data [4]. It can be seen that the ray method and the chord method (line 1) are much better correlated with each other than with line 2 obtained by the tangent method. This suggests that the linearization of the experimental deformation curve by the tangent method does not adequately describe the 
effect of humidity. In numerical calculations, the ray method is preferable to the chord method. Formula (5) better reflects the real deformation curves for different values of the increase in the moisture content of the samples.

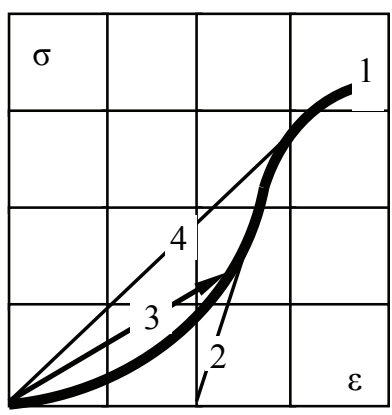

a

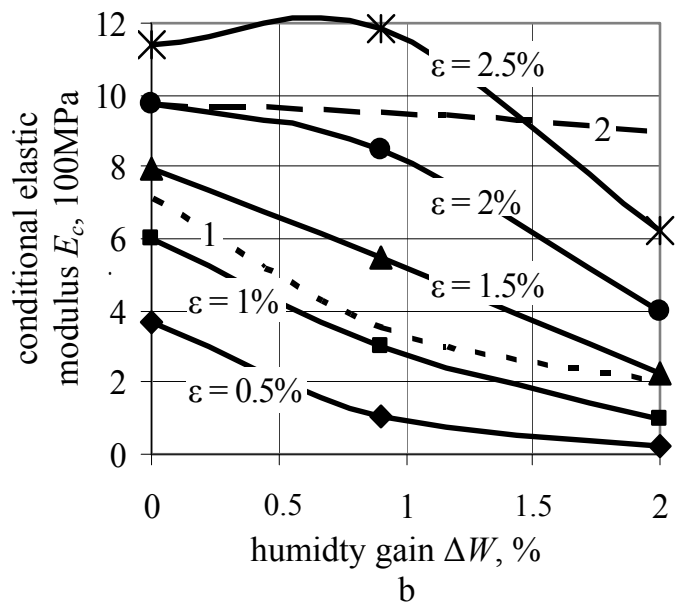

Fig. 3. Dependence of the conditional modulus of elasticity on the increase in humidity: a - diagram of methods for calculating the conditional elastic modulus; $b$ - dependence of the conditional modulus of elasticity on the increase in humidity.

Experiments and empirical dependencies $(3,4)$ show that during sample deformation $\varepsilon_{p h}=1 \%$, an increase in its moisture content by $0.9 \%$ reduces the axial stresses $\sigma$ by 1.3 times. And with an increase in humidity by $2 \%$, the axial stresses decrease by a factor of 3.2. This can be seen from the intersection points of curves $1,2,3$ of the vertical deformation line of $1 \%$ in Figure $2 b$. However, such high unloading rates are characteristic only for uniaxial compression. In a coal seam that is in a state of bulk rather than uniaxial compression, the decrease in stresses with an increase in humidity will not be so impressive. An approximate calculation using the formula (22) of [9] shows that the discharge from vertical stresses is $\sim 30 \%$. But this is enough to recognize the strain relief remains the main factor reducing the stresses in the reservoir at rock pressure not exceeding $0.5-0.6$ strength of coal.

\section{Conclusions}

Uniaxial compression perpendicular to the bedding of cubic coal samples from the $\mathrm{d} 4$ stratum of the Pokrovska mine with a central hole oriented along the load showed:

1) The deformation curve has the form of a one-term power dependence (2). This dependence has a concave character and differs noticeably from Hooke's law.

2) Numerical calculations of stresses using linear mechanics algorithms are best performed using a variable conditional modulus of elasticity. The conditional modulus of elasticity depends on the strain and is determined by formula (5).

3) The dependence of the modulus of elasticity on moisture is determined by the formulas (3-5). Their use does not require knowledge of natural moisture only its gain is important. With the same deformation, an increase in moisture content by $2 \%$ reduces the elastic modulus by 2.5 , and stress by a factor of 3.2 .

4) During hydraulic loosening of strata, strain relief is the main factor reducing stress in the reservoir at rock pressure not exceeding $0.5-0.6$ of coal breaking point. 
The authors thank Minieiev S.P. for systematic consulting and organizational support of research and Diakun R.A. for highly accurate registration of deformation curves.

\section{References}

1. Bulat A.F., Mineev S.P., Bryukhanov A.M., Nikiforov A.V. (2013). Development of classification procedure for gas-dynamic events in coal mines. Journal of Mining Science, 49 (6), 894-901

2. Mineev S.P. (2016). Forecast and ways of dealing with gas-dynamic phenomena in the mines of Ukraine. Mariupol: Vostochnyy izdatelskiy dom

3. Copticov V.P., Bocyy B.V., Mineev S.P. (2016). Improvement of methods and means of safe development of coal seams, prone to gas-dynamic phenomena. Donetsk: Promin

4. Mineev S.P., Potapenko A.A., Mkhatvari T.Ya. (2013). Improving the efficiency of hydromining of outburst coal seams. Donetsk: Skhidnyy vydavnychyy dim

5. Obschie polozheniya o privedenii plasta uglya $\mathrm{v}$ neudaroopasnoe sostoyanie nagnetaniem vody pod davleniem. (2018). Available at http://fccland.ru/gornyeudary/3103- html

6. Chernov O.I., Rozantsev E.S. (1975). Preparation of mine fields with gas-hazardous formations. Moskva: Nedra

7. Vasilyev, D., Polyakov, Y., Potapenko, A. (2013). Method of calculation of the minimum pressure of hydro breaking of the coal layer. Mining of Mineral Deposits. Leiden, The Netherlands: CRC Press/Balkema, 177-179,

8. Usov O.A., Polyakov Yu.E. (2016). Factors of the influence of coal hydrotreatment on the discharge of the near-bottom part of the massif. Geotechnichna mekhanika, 129, 166-172

9. Polyakov Yu.E. (2013). Deformation model of wet coal mass discharge. Geotechnichna mekhanika, 130, 125-136

10. Usov O.A. (2015). Conformity assessment of the linear law of water filtration to the real dynamics of its pressure change during injection into coal seams. Geotechnichna mekhanika, 120, 93-101

11. Usov O.A., Mineev S.P., Dyakun R.A. (2017). Laboratory studies of two-dimensional water filtration through coal samples. Miners Forum- 2017: materials of international conference, 4-7 December 2017, Dnipro - National Mining University, 298-307 